\section{Laennec, His Life and Times}

Roger Kervran, M.D. Translated from the French by D. C. Abrahams-Curiel. Pp. $x+213$. Oxford and London: Pergamon Press. 1960. 2 is.

Medical literature is not lacking in accounts of Laennec's work and of the importance of the contribution made by this great and talented physician to medical thought. Little, however, has been written hitherto about the personal life of the man himself and the details of his family life, many of which played so great a part in the shaping of his career. These are given to us in Dr. Kervran's book which throws, what must be for most English readers, a new light upon the picture of the great phthisiologist. Among the major influences which must have had a marked effect upon Laennec's outlook on life were his early introduction to the horrors of the French Revolution-the financial difficulties which beset him, for many if not most of which his popular but unsystematic father was largely responsible-and the wise counsel and constant guidance of his uncle Guillaume. Dr. Kervran has emphasized these points especially, though he gives us many more biographical details not directly connected with Laennec's medical and scientific activities.

The volume is of moderate size and cannot be said to constitute an exhaustive biography. A great deal of detail is given in the earlier chapters regarding the prominent people who surrounded Laennec's family during his childhood and adolescence. To be critical, we must perforce observe it struck us as being rather sketchily portrayed, and that the reader may find this part of the book a little lacking in atmosphere. Nevertheless, the facts are there, and have been set down with accuracy for the information of the student who seeks to know something of Laennec the Man as distinct from Laennec the Physician.

The book is convenient to hold; the format is attractive; and the print is excellent and clear. There is a good bibliography and an adequate index.

\section{Congenital Malformations}

Ciba Foundation Symposium. Editors: G. E. W. Wolstenholme, M.R.C.P.; C. M. O'Connor, B.sC. Pp. xii +308 , illustrated. London: J. \& A. Churchill. 1960. 45 s.

In the past, Ciba Foundation Symposia volumes have always maintained a high standard and this one is no exception. The book is a verbatim account of the symposium held in January 1960 at which 29 of the foremost authorities drawn from various disciplines discussed some aspects of congenital malformations. Included in this book are a lucid paper by Dr. Ford on chromosome abnormalities, a useful account of some of the variations in incidence of the commoner anomalies presented by Professor McEwen and some genetic problems by Professor Penrose. Various aspects of experimental teratology are dealt with in four separate papers, while the causes and morphogenesis of anencephaly are discussed by Professor Giroud. Amongst other papers on the association of hydramnios with congenital malformations and the role of diabetes and hyperthyroidism in the genesis of anomalies are included. The discussions which followed each paper, reported in full, are most informative and make interesting and sometimes amusing reading. The book is well presented and the illustrations on the whole are clear and well reproduced.

This volume is not intended to be a comprehensive reference book on all aspects of congenital malformation, but no medical library should be without it.

\section{Recommendations of the International Commission on Radiological Protection}

I.C.R.P. Publication 3. Report of Committee III on Protection against $X$-rays up to Energies of $3 \mathrm{MeV}$ and Beta- and Gamma-Rays from Sealed Sources. Pp. vi +84 . London and Oxford: Pergamon Press. I960.

This report brings up to date the information collected in Section D of the 1954 I.C.R.P. published as Supplement No. 6 of the British fournal of Radiology in 1955, and subsequently modified in 'The Code of Practice in the Protection of Persons Exposed to Ionizing Radiations' for N.H.S. and M.R.C. establishments published in 1957, and in several National Bureau of Standards handbooks.

In general, considerably more detail is included in the general recommendations than hitherto, and the data is presented in a helpful form, making for easy reference. It will, of course, comprise the definitive recommendations for some time. It is particularly welcome to have information on shielding of $\mathrm{Co}-60$ and $\mathrm{Cs}-\mathrm{I} 37$ radiation together with additional shielding graphs.

It is of interest that the three simple rules given in the I954 I.C.R.P. for reducing diagnostic X-ray exposures to patients and scattered radiation to operators have now been replaced by 12 recommendations (page 18 ).

The basic recommendations of the 1958 I.C.R.P. Publication I concerning maximum permitted dosage are reprinted in this volume, together with a short addendum resulting from the 1959 meeting of the I.C.R.P.

This book must, of course, be on the shelves of all those concerned with radiation protection against $\mathrm{X}$-, beta- and gamma-rays.

The Urological Aspects of Bilharziasis in Rhodesia

R. M. Honey, M.B., F.R.c.s.; M. GelFAND, c.B.E. M.D., F.R.C.P. Pp. 7I, illustrated. Edinburgh and

London: E. \& S. Livingstone Ltd. 1960. 7s. 6d.

As schemes for water conservation, irrigation, and hydro-electric power in tropical countries are planned, concern regarding schistosomiasis increases. The details of the life-cycle of the parasite and its intermediate snail-host have now been elucidated but the long-term effects of infection and especially of repeated infection in human beings are not adequately known. The writers of this monograph are specialists whose experience in Rhodesia is long and detailed. From the wealth of this experience they have extracted the material for this study. It is based on the records of 300 European and 100 African patients. The degree of infection, the different reaction to the infection, and the predominant clinical and urological findings, lead the writers to describe African bilharziasis as distinct from European bilharziasis. In the former the typical lesion in the bladder is the sandy patch with papillomata. Fibrosis in the bladder wall and calcification may result in a small-capacity bladder and in irregular stenosis and dilatation of the ureters. Reflux up the ureters is commoner in the African patients, and hydronephrosis is more often seen than in the Europeans. Surprisingly, acute cystitis due to secondary infection with $E$. coli is rare, and calculi were rarely found. In the African patient carcinoma may be found in association with urinary bilharzia whereas it was not encountered in these European patients.

This type of study, meticulously carried out and recorded, is of great value, and this monograph, adequately indexed, provides a most useful addition to knowledge of the long-term effects of this widespread infection. 